\title{
Efficiency, firm-specific and corporate governance factors of the Takaful insurance
}

\begin{abstract}
Purpose: Malaysia is recognised as an emerging country with a large Muslim population, making the Malaysian Takaful industry the largest Takaful market in the Southeast Asia region and, notably, one of the fastest growing markets globally. Malaysia is also the first country globally to implement a risk-based capital framework for Takaful. Therefore, the purpose of this paper is to identify the factors that influence the efficiency level (cost efficiency and technical efficiency) of the Takaful industry and to examine the effects of Takaful insurance firms' specific factors and corporate governance factors that influence the efficiency of Takaful insurance in Malaysia. Design/methodology/approach: In this paper, the efficiency level of the Malaysian Takaful industry was examined between 2011 and 2015. The sample consisted of 11 family Takaful and 8 general Takaful operators. Two-stage Data Envelopment Analysis (DEA) was used by first, conducting non-parametric frontier data envelopment analysis to obtain a DEA score for each operator. This was followed by panel regression with the DEA scores as the dependent variable and the insurance firms' specific factors and corporate governance factors as the independent variables. Findings: The results of DEA indicate that Takaful operators in general have allocative inefficiency but family Takaful is more cost efficient than general Takaful. Results of panel data analysis reveal that corporate governance factors do influence the cost efficiency but find no evidence on the firm-specific factors towards the cost efficiency and technical efficiency on Takaful operators. Board size and the proportion of non-executive directors impose a negative and significant relationship with cost efficiency, while proportion of Muslim directors in the board is not significant. Research limitations/implications: This paper focused solely on Malaysia which uses strict regulations governing the Takaful insurance market. Due diligence was also performed to minimise any limitation in the paper. It is proposed that future studies should examine this issue in greater detail by incorporating more data from other Muslim countries. Practical implications: The findings of this paper have significant implications for policymakers to understand the efficiency condition in the Takaful market. Takaful operators should maintain a small board size with a higher proportion of executive directors, given they could improve the level of effective decision-making to enhance the cost efficiency. As corporate governance factors are significant, Takaful operators in Malaysia should also undertake transparent disclosure practice and reporting such as providing adequate and relevant information related to Shariah compliance and principles to provide a robust foundation as the Takaful market leader regarding Takaful regulations globally. Social implications: The consumer is able to make a better decision when choosing Takaful insurance company to protect their interests. Originality/value: No similar paper has been undertaken to the best of the researcher's knowledge using similar research design and scope to investigate the efficiency of Takaful insurance as in this paper. Takaful insurance is a rapidly growing industry in Malaysia, setting a prime example to other countries globally. Malaysia was selected for this study, as it is the only nation that has implemented the most extreme regulation in the Takaful insurance market.
\end{abstract}


Keyword: Insurance; Corporate governance; Efficiency; DEA; Islamic financial institution 